\title{
Steam reheater with helical tube bundle for wet steam turbine
}

\author{
Mikle Egorov ${ }^{1,2, *}$, Alexander Ivanov ${ }^{1}$, Ivan Kovalenko ${ }^{2}$, Irina Krectunova ${ }^{2}$, Nadezhda Litvinova ${ }^{2}$, and Elena Popova ${ }^{1,3}$ \\ ${ }^{1}$ Peter the Great St. Petersburg Polytechnic University, Russia, 195251 Saint-Petersburg, Polytechnicheskaya 29 \\ ${ }^{2}$ St. Petersburg State University of Aerospace Instrumentation, Russia, 190000 St. Petersburg, Bolshaya Morskaya str. 67 \\ ${ }^{3}$ Concern Avrora Scientific and Production Association JSC, Russia, 194021 Saint-Petersburg, Karbysheva str. 15
}

\begin{abstract}
Since steam heat exchangers, used at steam cycle of Russian nuclear power stations, were designed while the knowledge about the separation and the heat exchange processes was limited, deviations between its empirical and theoretical characteristics occur. This limitation also determined application of heating pipes with simple straight shape rather than curved. This study explores a steam heat exchanger with helical heating pipes. It was shown that the model may work stably within the range of parameters, simulating work conditions of the moisture separator and steam reheater at Leningrad nuclear power plant. The experiment included processing of pure water steam as well as mixture of steam and nitrogen. It was obtained a relationship between empirical the heat transfer coefficient and the steam mass flow rate. It was noted that presence of incondensable gas does not affect significantly the heat transfer from the coils, processing high pressure steam.
\end{abstract}

\section{Introduction}

Identification of the sections of $0.4 \mathrm{kV}$ power Moisture separators and steam reheaters (MSR) are widely used at Russian nuclear power plants (NPP) with VVER, RBMK reactor types [1-3]. These installations process steam between the high pressure stage of the turbine the low pressure stage. MSR improve thermal parameters of steam at all modes of the reactor and even in the mode with natural circulation of the coolant $[4,5]$. Application of such equipment pursues several goals such as to improve the efficiency of the steam cycle and to avoid decay of turbine parts. The erosion process may occur when steam, leaving the high pressure stage, becomes saturated with moisture that may erode blades of the following turbine stages [6-8].

Furthermore, water droplets continuously contacting with warm surface of heating pipes induce cyclic stress which results in pipe ruptures. Notably, that pipes of horizontal helical shape are more prone to breaks in contrast to that of vertical and straight shape. This circumstance determined limited usage of MSR with helical coils and widespread of models with straight heating elements.

At present, different constructions of MSR are in use. Since theories of steam separation and heat exchange were not well developed at the time when MSR were engineered, various deviations between simulated and real characteristics of MSR can be observed. For instance:

- uneven profile of the outgoing steam from the separator which results in moisture transfer to reheater and consequently into nonattainment of the designed temperature value [9];
- appearance of overheated and overcooled zones within the heating pipes bundle because of uneven flow spread and different length of steam supply pipes. This circumstance creates undesirable tensions, and generates condensation areas, initiating vibration, respectively. Condensation from a two phase flow is more complex than that from a single phase because it hinders heat transfer between mediums as shown in [10]. Therefore, complex models like Hammouda are used instead of ordinary heat exchange formulas for the heat transfer coefficient estimation of the pipe bundle [11]. Recent studies show satisfactory precision of the approach [1214].

In addition to these deviations, other disadvantages were discovered:

- high friction loss along the steam duct due to arrangement of moisture separator above MSR (which is common for VVER-440 project);

- appearance of incondensable gases (ICG) in heating pipes diminishes heat exchange between the heating steam and the pipe surface [15-16];

- vertical arrangement of heating pipes in the MSR bundle (which is typical for VVER-1000 project) has lower heat transfer coefficient in contrast to the horizontal arrangement. Furthermore, many researches were conducted within the last decades aiming on heat transfer intensification [17-19].

In order to improve disadvantages of existing constructions, several modernizations were made. For instance, after redesigning of separating bundles of the MSR model "SPP-500-1" at the Leningrad NPP, located near Saint-Petersburg, Russia, several goals were achieved. On first, uneven moisture distribution was

* Corresponding author: mikhail.yu.egorov@gmail.com 
eliminated and on second, the moisture concentration value reached its calculated range [20-21].

Aiming to overcome disadvantages, which are inherent to MSR with vertical arrangement of heating pipes, two experimental heat exchangers were designed. First unit, which consisted of two full-scale helical tubes and shell, justified that horizontal coils may work steady.

\subsection{Research objectives}

Since the first unit showed satisfactory results, it was suggested to increase the number of heat exchanging pipes in order to simulate construction of the MSR heating section.

It was also suggested to expand experimental objectives as follows:

- justify multicoil unit's ability to perform stably;

- estimate the heat transfer coefficient at nominal mode and its deviation from the simulated coefficient;

- study how presence of ICG in steam $(0,02 \%$ by mass) affects heat transfer and hydrodynamic stability of the unit (simulating work conditions, occurring at the NPP with single loop reactor type).

\section{Materials and methods}

The multicoil experimental unit consist of 10 doubletwisted helical tubes, mounted inside cylindrical shell. A $3 \mathrm{~d}$ model of the unit, which was designed by authors, illustrated at the Fig. 1.

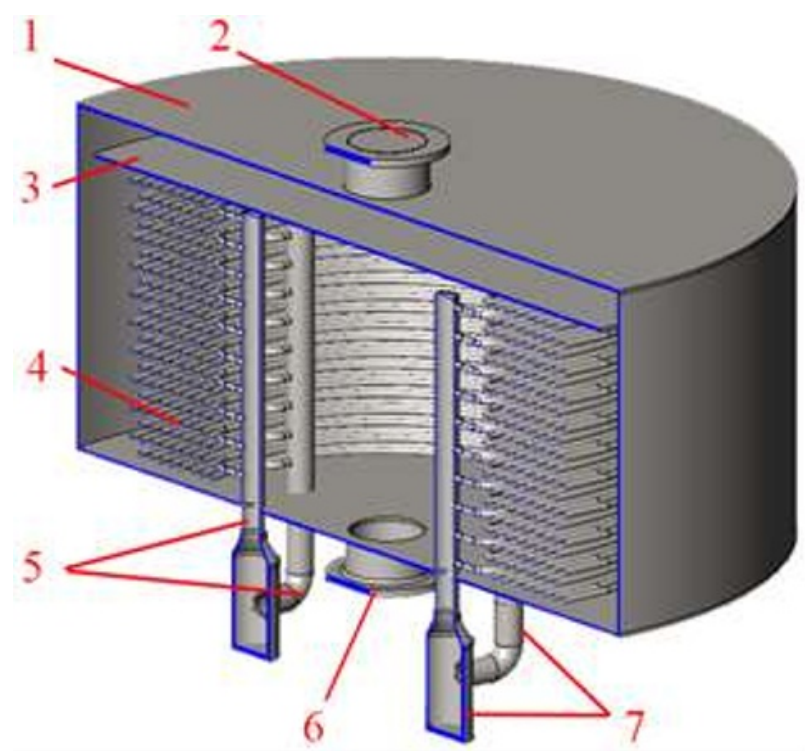

Fig. 1. Experimental multicoil heat exchanger model cross section: 1 - shell; 2 - LP steam inlet flange; 3 - sheet; 4 - coil bundle; 5 - HP steam inlet channel; 6 - LP seam outlet flange; 7 - HP steam-condensate outlet channel.

The unit has two steam loops: low pressure (LP) and high pressure (HP). From the inlet nozzle, the HP vapor is distributed between two vertical steam channels and then it is spread among 10 helical pipes. Steam transfers its heat to pipe's walls and condenses partially. The steam and condensate mixture flows towards one of two vertical condensate channel; then it fills up the condensate tank and drains after cooling.

When the LP steam reaches the unit's inlet, it flows through the gap between flat round sheet and cylindrical shell. Then, it goes around several helical coils and warms up. At last, reheated steam is supplied back.

Each heating pipe is plain and circular in cross section with diameter $\varnothing 18 \mathrm{~mm}$, wall thickness of $2 \mathrm{~mm}$ and length of $8.5 \mathrm{~m}$. Tubes are twisted in flat spirals (Archimedes' spirals) with step of $20 \mathrm{~mm}$. Its dimensions are as follows: about $\varnothing 1,0 \mathrm{~m}$ (internal) and $\varnothing 1,7 \mathrm{~m}$ (external). Coils has square layout with inline pattern in the front section. The total surface of 20 spirals is $F \sim 46.2 \mathrm{~m} 2$.

Unit's cylindrical shell with diameter is $2100 \mathrm{~mm}$ is covered by insulation made from clay bricks, placed with a small gap between, and surrounded by external metal cylindrical shell. All unit parts were made of carbon steel alloy 'steel 20'.

During the experiment, the unit's performance was tested within the range of parameters as shown in the Table 1 below.

Table 1. Experimental unit's parameters range.

\begin{tabular}{|c|c|c|}
\hline Parameter & LP & HP \\
\hline Steam flow rate $G, \mathrm{~kg} / \mathrm{s}$ & $1.9-5.3$ & $0.18-0.38$ \\
\hline Incoming flow temperature $t_{\mathrm{in}}$, & $134-170$ & $232-301$ \\
\hline Pressure $P, \mathrm{MPa}$ & $0.18-0.27$ & $2.62-4.05$ \\
\hline
\end{tabular}

After every change of the mass flow rate, the empirical heat transfer coefficient $\mathrm{K}_{\mathrm{emp}}, \mathrm{W} / \mathrm{m}^{2} \mathrm{~K}$ was estimated using following equation:

$$
K_{\text {emp }}=\frac{G^{h p}\left(r+C_{P}\left(t_{\text {in }}^{h p}-t_{\text {out }}^{h p}\right)\right.}{F \Delta \bar{t}}
$$

where

$G^{h p}$ - condensate flow rate, $\mathrm{kg} / \mathrm{s}$;

$r$ - enthalpy of vaporization, $\mathrm{J} / \mathrm{kg}$ [22];

$C_{P}$ - isobaric heat capacity, $\mathrm{J} / \mathrm{kg} \mathrm{K}$;

$t_{i n}^{h p}$ - tubeside inlet temperature, $\mathrm{K}$;

$t_{\text {out }}^{\text {hp }}$ - tubeside outlet temperature, $\mathrm{K}$;

$F$ - coil surface area, $\mathrm{m}^{2}$;

$\Delta \bar{t}-$ logarithmic mean temperature difference, $\mathrm{K}$, which can be founded using following equation [23]:

$$
\Delta \bar{t}=\frac{\left(t_{\text {in }}^{h p}-t_{\text {in }}^{l p}\right)-\left(t_{\text {out }}^{h p}-t_{\text {out }}^{l p}\right)}{\ln \frac{\left(t_{\text {in }}^{h p}-t_{\text {in }}^{l p}\right)}{\left(t_{\text {out }}^{h p}-t_{\text {out }}^{l p}\right)}}
$$

where:

$\mathrm{t}_{\text {in }}^{\text {lp }}$ - shellside inlet temperature, $\mathrm{K}$;

$\mathrm{t}_{\text {out }}^{\text {lp }}$ - shellside outlet temperature, $\mathrm{K}$.

The theoretical linear heat transfer coefficient $\mathrm{K}_{\text {theor }}$, $\mathrm{W} / \mathrm{m}^{2} \mathrm{~K}$ can be obtained from the relationship: 


$$
K_{\text {Theor }}=\frac{1}{\frac{1}{\alpha_{1} d_{1}}+\frac{1}{2 \lambda_{\text {shell }}} \ln \frac{d_{2}}{d_{1}}+\frac{1}{\alpha_{2} d_{2}}}
$$

where:

$d_{1}$ - external diameter of the coil, $\mathrm{m}$;

$d_{2}$ - internal diameter of the coil, $\mathrm{m}$;

$\alpha_{1}$ - heat transfer coefficient of the pipe wall (in case the flow is crossing the heating pipes bundle), $\mathrm{W} / \mathrm{m}^{2} \mathrm{~K}$.

The coefficient $\alpha_{1}$ can be computed from the following equation:

$$
\alpha_{1}=0.2 \operatorname{Re}^{0.64} \operatorname{Pr}^{0.35}
$$

where Re - the Reynolds number which can be computed from the following relationship:

$$
\operatorname{Re}=\frac{\bar{v} d_{1}}{v}
$$

where $\bar{v}$ - average velocity of the HP flow, $\mathrm{m} / \mathrm{s}$;

$d_{1}$ - external diameter of the pipe, $\mathrm{m}$;

$v$ - kinematic viscosity of the fluid, $\mathrm{m}^{2} / \mathrm{s}$;

$\operatorname{Pr}-$ the Prandtl number, given as:

$$
\operatorname{Pr}=\frac{C_{p} \mu}{\lambda}
$$

where:

$\mu$ - dynamic viscosity, Pa s ;

$\lambda$ - thermal conductivity, $\mathrm{W} / \mathrm{m} \mathrm{K}$.

In case condensation occurs inside heating pipes, the heat transfer coefficient $\alpha_{2}, \mathrm{~W} / \mathrm{m}^{2} \mathrm{~K}$ can be determined using the equation $\alpha_{2}=0,02 A C_{z} q^{-0,5} l^{0,3} d_{2}^{0,2}$.

\section{Results}

1. The empirical heat transfer coefficient $K_{\text {emp }}, \mathrm{W} / \mathrm{m}^{2} \mathrm{~K}$ was estimated while the steam mass flow of both: HP and LP was changed in a wide range. The result of the estimation can be seen from the Fig. 2.

As it can be noted from the Fig. 2, the heat transfer coefficient rises steadily with increase of steam flow mass rate. Though the heat transfer coefficients of the 10-coils model and that 2-coil model follow similar pattern, the gap between coefficients of models is $\sim 30 \%$.

A relationship between the heat transfer coefficient, estimated experimentally, and the flow mass rate of the 10-coil model can be expressed using following equation:

$$
K_{\text {emp }}=4,546(\gamma W)^{2}+76,411 .
$$

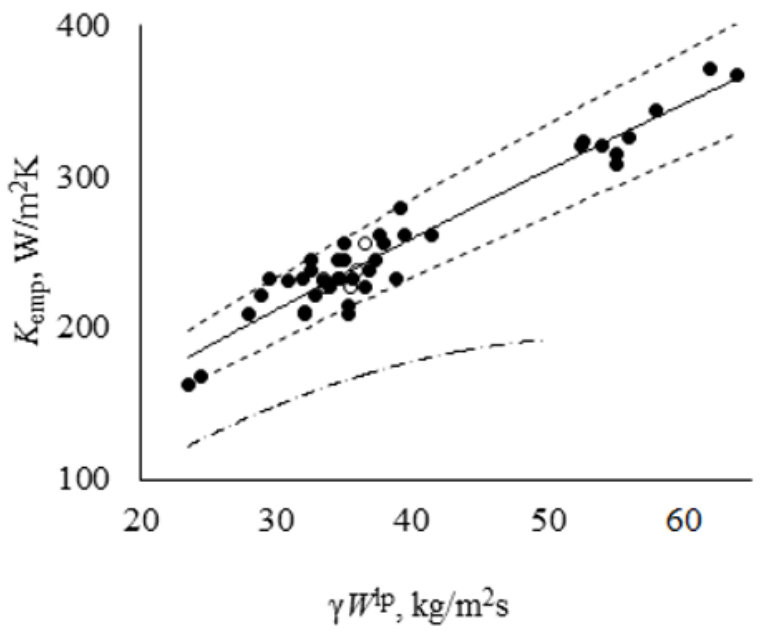

Fig. 2. Empirical heat transfer coefficient by the flow mass rate of low pressure steam $\gamma W$ :

- experiment with pure vapor;

- experiment with mixture of vapor and nitrogen;

- - approximation (10-coils model);

- - - approximation (2-coils model)..

Analyzing the equation (1) it can be noted that the heat transfer coefficient rises steadily with increase of steam flow mass rate. Though the heat transfer coefficients of the 10-coils model and that 2-coil model follow similar pattern, the gap between coefficients of models is $\sim 30 \%$.

2. It is observed a $18 \%$ difference between theoretical and empirical values of the heat transfer coefficient as shown at the Fig. 3 .

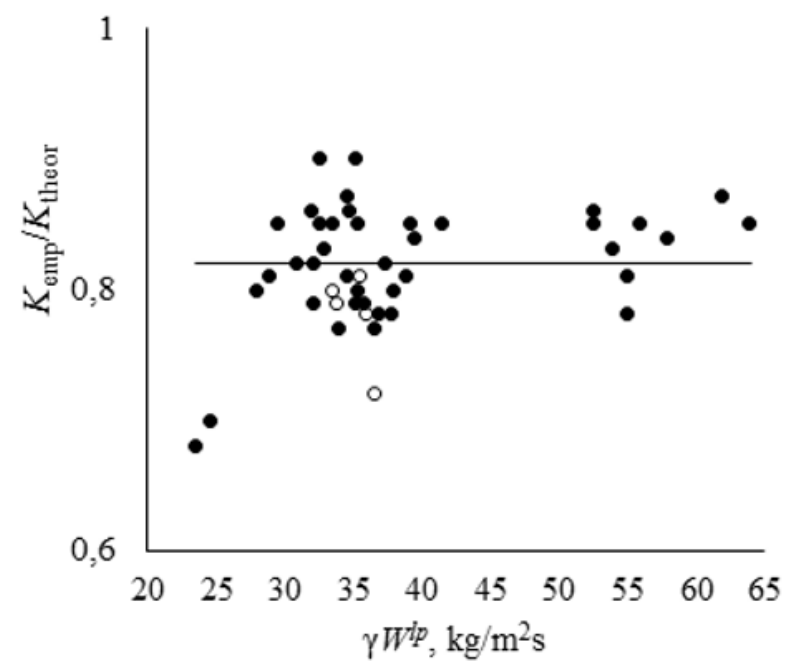

Fig. 3. The empirical to theoretical heat transfer coefficient ratio by the low pressure steam mass flow rate:

- experiment with pure vapor;

- - experiment with mixture of vapor and nitrogen;

- - approximation (10-coils model).

3. Observing Fig. 2 and Fig. 3 it can be seen that results of experiment with pure steam and that with the nitrogen does not differ significantly. 


\section{Discussion}

A remarkable deviation between heat transfer coefficients of 10-coil model and that of 2-coil model, which can be seen at the Fig. 2, caused by:

- better precision while 10-coil model manufacturing;

- more steady flow which multicoil bundle assure by contrast to that of 2-coil model.

As it can be inferred from the Fig. 2, there is a positive relationship between the empirical heat transfer coefficient and HP mass flow rate value. The densest dots cluster on the left of the figure shows boundaries of the nominal mode. The cluster center indicates the coefficient value in nominal mode which is $\mathrm{K}_{\mathrm{emp}}=250$ $\mathrm{W} / \mathrm{m}^{2} \mathrm{~K}$ when $\gamma W^{\mathrm{p}}=37,5 \mathrm{~kg} / \mathrm{m}^{2}$.

Theoretical values of linear heat transfer coefficient from inner side are larger than that from outer side. Thus, overall heat transfer coefficient of the model mainly depends from factors, affecting condensation such as: position coils in model's space, medium velocity, inner and outer diameter of the pipe; overall length of coil and the number of loops, inner surface roughness and other [24].

When experiment was completed, empirical heat transfer coefficients were benchmarked with its theoretically computed values. As it can be seen from the Fig. 3, empirical values lag behind theoretical because of:

- presence of baffles, partly obscuring coil surface but needed for coils fixation;

- poor heat exchange of coils, that located the top and in the bottom of the bundle, due to imperfect steam distribution which is determined by the shell and the plate geometry.

Absence of impact of incondensable gas on the heat transfer coefficient, which can be observed at the Fig. 2 and Fig. 3, can be explained by high pressure of HP steam. This finding matches with [25] though discharge of incondensable gases from the model is suggested in [16].

\section{Conclusion}

In result of the study it was obtained:

- the multicoil model may work stably within wide range of parameters and modes, which corresponding to that of moisture separator and reheater MSR, installed at the Leningrad NPP;

- 3D-model of the experimental unit;

- the empirical heat transfer coefficient lags behind theoretical. In nominal mode its value is $250 \mathrm{~W} / \mathrm{m}^{2} \mathrm{~K}$;

- incondensable gas does not hinder significantly the heat transfer from the coil surface.

\section{References}

[1] G. Li, Ch. Yan, J. Wang, Annals of Nuclear Energy 73 (2014)

[2] Y. Liu, Zh. Qu, Energy Procedia 105 (2017)
[3] W. Xinjun, Ch. Peng, X. Jinwei, Zh. Zijie, Journal of Mechanical Science and Technology 29, 8 (2015)

[4] V. Bezlepkin, I. Kukhtevich, S. Svetlov, S. Alekseev, A. Solodovnikov, A. Molchanov, Y. Krylov, A. Blagoveshchenskij, O. Krektunov, Tyazheloe Mashinostroenie 8 (2004)

[5] A. Blagoveshchenskii, S. Bor, M. Konovich, V. Mityukov, V. Sokolov, B. Shumskii, S. Vygovskii, A. Pinegin, L. Bogachek, V. Bai, N. Ignat'ev, Thermal Engineering 51, 2 (2004)

[6] N.I. Kolev, Multiphase Flow Dynamics 5 (Berlin, Springer, 2011)

[7] L. Liu, B. Bai, Nuclear Engineering and Design 298 (2016)

[8] Zh. Huang, L. Qianfeng, Q. Benke, B. Hanliang, Ch. Feng, Annals of Nuclear Energy 92 (2016)

[9] V. Legkostupova, A. Sudakov, St. Petersburg Polytechnic University Journal of Engineering Science and Technology 23, 3 (2017)

[10] N. Agafonova, I. Paramonova, Thermal Engineering 60, 3 (2013)

[11] S. Alekseev, Y. Ilyukhin, V. Kukhtevich, I. Paramonova, S. Svetlov, V. Sidorov, High Temperature 37, 4 (1999)

[12] N. Agafonova, I. Paramonova, Thermal Engineering 61, 8 (2014)

[13] N.D. Agafonova, I.L. Paramonova, Journal of Engineering Physics and Thermophysics 89, 4 (2016)

[14] M. Gorpinyak, A. Solodov, Thermal Engineering 66, 6 (2019)

[15] G. Bychkova, V. Melikhov, O. Melikhov, A. Bel'skii, Thermal Engineering 52, 3 (2005)

[16] V. Sharapov, M. Malikov, Power Eng.: Research, Equipment, Tech., 5-6 (2007)

[17] S. Sapozhnikov, V. Mityakov, A. Mityakov, A. Babich, E. Zainullina, Technical Physics Letters 45, 4 (2019)

[18] S. Sapozhnikov, V. Mityakov, V. Seroshtanov, A. Gusakov, J. Phys.: Conf. Ser. 1421, 012064 (2019)

[19] G. Lepesh, A. Lepesh, S. Luneva, J. Technicotehnologicheskie problemy servisa4, 38 (2016)

[20] V. Legkostupova, A. Sudakov, St. Petersburg Polytechnic Univ. J. of Eng. Sci. and Tech. 4, 254 (2016)

[21] V. Legkostupova, A. Sudakov, Thermal Eng. 62 , 3 (2015)

[22] A. Alexandrov, B. Grogor'ev, Tables of thermophysical properties of water and steam (Moscow, MEI, 1999)

[23] P.L. Kirillov, A.V. Zhukov, N.I. Loginov, Reference book on thermohydraulic calculations in nuclear power industry (Moscow, IzdAT, 2013)

[24] D.I. Volkov, Energomashinostroenie 6 (1969)

[25] A. Tugov, E. Ivanov, Y. Radin, R. Shuvalov, V. Guseva, Thermal Engineering 53, 7 (2006) 